\title{
Endoscopic Valve Removal >180 Days since Implantation in Patients with Severe Emphysema
}

\author{
Daniela Gompelmann ${ }^{a, b}$ Vasiliki Gerovasili ${ }^{c}$ Konstantina Kontogianni ${ }^{a}$, b \\ Maren Schuhmann $^{\mathrm{a}}$ Ralf Eberhardt ${ }^{\mathrm{a}, \mathrm{b}}$ Felix J.F. Herth ${ }^{\mathrm{a}, \mathrm{b}}$ Markus Polke ${ }^{\mathrm{a}}$ \\ a Pneumology and Critical Care Medicine, Thoraxklinik, University of Heidelberg, Heidelberg, Germany; \\ ${ }^{\mathrm{b}}$ Member of the German Center for Lung Research, Heidelberg, Germany; ${ }^{\mathrm{C}}$ Respiratory and Transplant Medicine \\ Department, Harefield Hospital, Royal Brompton and Harefield NHS Foundation Trust, London, UK
}

\section{Keywords}

Chronic obstructive pulmonary disease - Emphysema .

Endoscopic valve therapy

\begin{abstract}
Background: Valve implantation provides a reversible effective therapy in a selected group of emphysema patients. Knowing predictors for successful therapy, the rate of treatment failure has decreased. Some patients, however, do not benefit, so that the valves may have to be removed. Objectives: To assess implant-related events, complications during valve removal, and clinical outcome after endoscopic procedure. Methods: The data of 76 consecutive emphysema patients who underwent valve removal $>6$ months since implantation were collected. Results: Seventy-six patients (mean age 62 years, 54\% male) underwent removal of all valves after a mean time of 624 days (193-3,043 days) since implantation. Granulation tissue was observed in $39.5 \%$ (30/76) and significant secretion in 34.2\% (26/76). In 5.3\% (4/76), valve removal was complicated requiring another bronchoscopy in 2 of them. In 5.3\% (4/76) of the patients, one valve could not be removed and remained in situ. Bleeding requiring intervention occurred in 3.9\% (3/76) during valve removal. Following bronchoscopy, there was a need
\end{abstract}

for antibiotics in 34.2\% (26/76), glucocorticosteroids in $1.3 \%$ $(1 / 76)$, and both in $6.6 \%(5 / 76)$ due to productive cough or chronic obstructive pulmonary disease (COPD) exacerbation. Due to respiratory failure, invasive ventilation or noninvasive ventilation was necessary in $2.6 \%(2 / 76)$ and $6.6 \%$ (5/76), respectively, following procedure. No statistical significant change in lung function was observed following valve removal. Conclusions: Valve removal after $>6$ months since implantation is feasible and associated with an acceptable safety profile. However, close monitoring of these patients with limited pulmonary reserve is recommended with particular attention to COPD exacerbations and respiratory failure.

๑ 2018 S. Karger AG, Basel

\section{Introduction}

Endoscopic valve therapy is one of the therapeutic approaches aiming for lung volume reduction in patients with advanced chronic obstructive pulmonary disease

Presentation as abstract "Endoscopic Valve Removal >180 Days since Implantation in Patients with Severe Emphysema," ERS International Congress, September 2017, Milan, Italy.

\section{KARGER}

(C) 2018 S. Karger AG, Basel

E-Mail karger@karger.com

www.karger.com/res
PD Dr. med. Daniela Gompelmann

Pneumology and Critical Care Medicine

Thoraxklinik at University of Heidelberg

Röntgenstrasse 1, DE-69126 Heidelberg (Germany)

E-Mail daniela.gompelmann@ @ed.uni-heidelberg.de 
Fig. 1. Timeline.

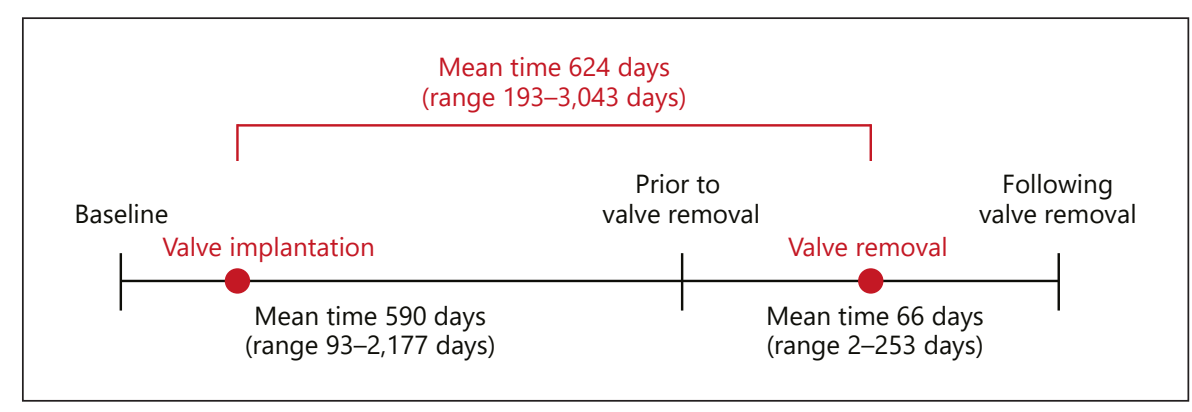

(COPD) and emphysema. Valve implantation results in lobar atelectasis in a selected cohort of patients and thus leads to improvement of symptoms and long-term outcome [1-5]. Besides valve placement as the best-studied endoscopic lung volume reduction technique, coil implantation, bronchoscopic thermal vapor ablation, or polymeric lung volume reduction also aim at reduction of hyperinflation. These different endoscopic methods differ not only in the implementation but also in their mechanism of action and complication spectrum. One essential prerequisite for successful outcome of valve placement is the absence of interlobar collateral ventilation, whereas the other methods can also be successfully used in patients with significant collateral ventilation. However, one crucial advantage of valve therapy compared to the other endoscopic approaches is its reversibility [1].

In general, valve removal is straightforward endoscopically by using a flexible forceps under conscious sedation or general anesthesia. In randomized controlled trials (RCTs) related to valve therapy, the authors described temporary or permanent valve removal in 16 out of 167 COPD patients within the first 3 or 6 months following valve placement [2-5]. Reasons for valve removal were pneumothorax, torsion of the left lower lobe bronchus after left upper lobe therapy, treatment failure, cough, and valve migration. In these patients, one fatal tension pneumothorax following valve removal occurred [2]. However, there are no comprehensive data on complications related to valve removal $>6$ months since implantation.

Furthermore, there are only limited data about implant-related events. Valves are foreign bodies that may irritate the bronchial mucosae and induce granulation tissue formation. In the first RCT known as VENT, granulation tissue formation was described in $2.3 \%$ and bronchial trauma in $0.5 \%$ of the patients [6].
This retrospective analysis evaluates the implant-related events and the complications associated with valve removal $>180$ days after implantation.

\section{Methods}

In this retrospective cohort study, all consecutive emphysema patients who underwent endoscopic valve therapy between 2005 and 2013 at the Thoraxklinik of the University of Heidelberg were evaluated. The data of all patients who underwent permanent valve removal $>6$ months since implantation or since the last change of all valves were collected. Reasons for valve removal, complications, and outcome were assessed. The local ethics committee of Heidelberg (S-609/2012) approved the protocol of this trial.

\section{Subjects and Assessment of Clinical Data}

Patients enrolled in this analysis underwent placement of endobronchial valves (EBV, Pulmonx, Switzerland) and/or intrabronchial valves (IBV, Olympus, Japan) for the treatment of severe emphysema that was confirmed by lung function tests and multidetector computed tomography scan. As the impact of collateral ventilation as predictor for successful valve therapy was not known until 2010, also patients with significant collateral ventilation were treated by valves from 2005 to 2010 and were included in this retrospective trial. Only data of patients who underwent permanent removal of the valves $>6$ months since implantation or since the last change of all valves were assessed. Implant-related complications and adverse events that occurred during or immediately following valve removal were collected by reviewing medical and bronchoscopic reports. Lung function parameters (vital capacity, forced expiratory volume in $1 \mathrm{~s}\left[\mathrm{FEV}_{1}\right]$, residual volume, and total lung capacity), were collected from each patient at baseline prior to valve placement, prior to valve removal, and following valve removal (Fig. 1).

\section{Statistical Analysis}

Data are presented as mean \pm standard deviation, minimum and maximum, or $n$ and \% for frequency data. Changes in lung function parameters from baseline to follow-up examinations were expressed by descriptive statistics (mean, range, standard deviation). Statistical comparison for the baseline examinations versus follow-up examinations were made using the paired two-sided $t$ test. $p$ values $<0.05$ were considered as statistically significant. 
Fig. 2. Endoscopic image. Granulation tissue formation around an endobronchial valve.

Fig. 3. Endoscopic image. Granulation tissue formation around an intrabronchial valve.

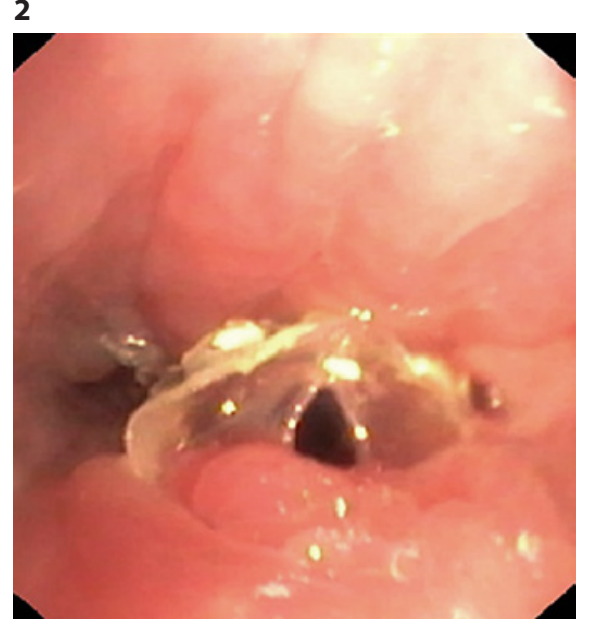

3

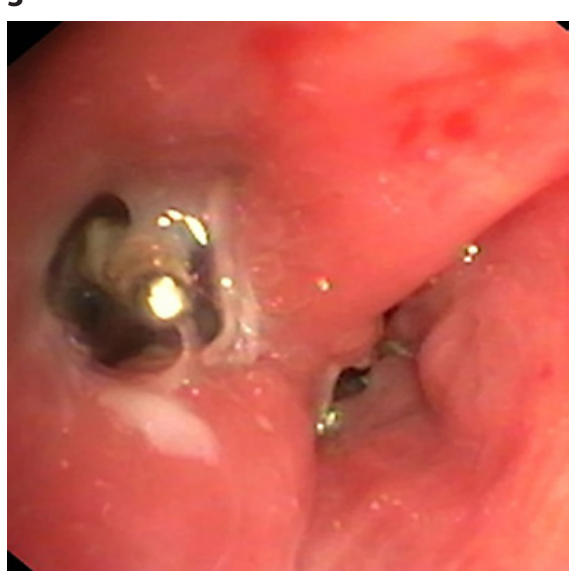

\section{Results}

From 2005 to 2013, 76 out of 449 emphysema patients (mean age 62 years, 54\% male) treated with valves underwent permanent valve removal $>180$ days after valve placement or after the last change of all valves (mean time 624 days [193-3,043 days]). In all these 76 patients, at least one of the valves had remained in situ over the entire time period. Following valve implantation, radiological follow-up had revealed a complete lobar atelectasis in 4 and pneumothorax as anticipated complication in 8 out of the 76 patients. In 2 patients, pneumothorax and lobar atelectasis had occurred. In 62 out of the 76 patients, neither lobar atelectasis nor pneumothorax had been confirmed during the time of valve therapy. Indication for valve removal was treatment failure in $85.5 \%$ (65/76), poststenotic pneumonia in $9.2 \%$ (7/76), hemoptysis in $3.9 \%(3 / 76)$, or lung cancer prior to radiotherapy in $1.3 \%$ $(1 / 76)$. Valves were permanently removed from the right upper lobe and middle lobe as combined target lobes in $28.9 \%$ (22/76), from the left lower lobe in $27.6 \%(21 / 76)$, from the right lower lobe in $21.1 \%(16 / 76)$, from the left upper lobe in $11.8 \%(9 / 76)$, from the right upper lobe in $9.2 \%(7 / 76)$, and from both upper lobes in $1.3 \%(1 / 76)$. During valve removal, 50 out of the 76 patients had no anticoagulant therapy (therapeutic anticoagulation was stopped prior to the procedure in 7 patients), 25 patients received low-dose acetylsalicylic acid for concomitant vascular disease, and 1 patient was on therapeutic-dose heparin.

\section{Implant-Related Events and Procedure-Related Complications}

During the bronchoscopic procedure, granulation tissue was observed in 39.5\% (30/76) (Fig. 2,3) and clinical significant secretions in $34.2 \%(26 / 76)$. In all patients, rigid bronchoscopy combined with flexible bronchoscopy was performed under general anesthesia for valve removal as is the standard in our institution. In $5.3 \%$ of the patients (4/76), valve removal was technically complicated due to granulation tissue and bleeding and required another bronchoscopy in $2.6 \%(2 / 76)$ to remove all valves. In $5.3 \%(4 / 76)$ of the patients, one valve could not be removed and remained in situ. Bleeding requiring intervention occurred in $3.9 \%$ (3/76) during endoscopic valve removal. Two out of these 3 patients were on low-dose acetylsalicylic acid. In all 3 patients, topical vasoconstrictive agents were instilled in the bleeding airway; additional endobronchial gauze tamponade was necessary in 2 patients to control the bleeding.

Following bronchoscopic valve removal, antibiotics, glucocorticosteroids or both were administered due to worsening of dyspnea, productive cough, or pulmonary infiltration in $34.2 \%(26 / 76)$, in $1.3 \%(1 / 76)$, and in $6.6 \%$ (5/76), respectively. Due to respiratory failure, invasive ventilation was necessary in $2.6 \%(2 / 76)$ and noninvasive ventilation in $6.6 \%(5 / 76)$.

One patient died 120 days following removal of valves from the right lower lobe due to pneumonia and severe bleeding. These valves had been in situ for 491 days. This patient was on anticoagulant therapy that was stopped prior to endoscopic valve removal. The valve removal was technically simple without any bleeding and the therapeutic anticoagulation was restarted postprocedural. Af- 
Table 1. Patient characteristics prior to valve placement

\begin{tabular}{lcc}
\hline & $n$ & Mean \pm SD \\
\hline VC, L & 76 & $2.54 \pm 0.86$ \\
$\mathrm{VC}^{\circ} \%$ & 76 & $73.2 \pm 19.4$ \\
$\mathrm{FEV}_{1, \mathrm{~L}}$ & 76 & $0.82 \pm 0.24$ \\
$\mathrm{FEV}_{1}, \%$ & 76 & $30.5 \pm 8.0$ \\
$\mathrm{RV}, \mathrm{L}$ & 76 & $5.31 \pm 1.3$ \\
$\mathrm{RV}, \%$ & 76 & $247.4 \pm 54.2$ \\
TLC, L & 76 & $7.91 \pm 1.71$ \\
TLC, \% & 76 & $135.9 \pm 19.5$ \\
\hline
\end{tabular}

VC, vital capacity; $\mathrm{FEV}_{1}$, forced expiratory volume in $1 \mathrm{~s} ; \mathrm{RV}$, residual volume; TLC, total lung capacity.
Table 3. Changes of lung function parameters from the timepoint before valve removal to the timepoint after valve removal after a mean time of 66 days (range 2-253 days)

\begin{tabular}{lccc}
\hline & $n$ & Mean $\pm \mathrm{SD}$ & $p$ value \\
\hline$\Delta \mathrm{VC}, \mathrm{L}$ & 59 & $-0.02 \pm 0.41$ & 0.622 \\
$\Delta \mathrm{VC}, \%$ & 59 & $-0.67 \pm 12.47$ & 0.659 \\
$\Delta \mathrm{FEV}_{1}, \mathrm{~L}$ & 59 & $0.02 \pm 0.11$ & 0.079 \\
$\Delta \mathrm{FEV}_{1}, \%$ & 59 & $1.06 \pm 5.24$ & 0.062 \\
$\Delta \mathrm{RV}, \mathrm{L}$ & 59 & $-0.12 \pm 0.89$ & 0.851 \\
$\Delta \mathrm{RV}, \%$ & 59 & $-4.79 \pm 41.01$ & 0.813 \\
$\Delta \mathrm{TLC}, \mathrm{L}$ & 59 & $-0.14 \pm 0.84$ & 0.894 \\
$\Delta \mathrm{TLC}, \%$ & 59 & $-1.86 \pm 14.69$ & 0.833 \\
\hline
\end{tabular}

VC, vital capacity; $\mathrm{FEV}_{1}$, forced expiratory volume in $1 \mathrm{~s}$; RV, residual volume; TLC, total lung capacity.

terwards, however, there was the need for antibiotic therapy and noninvasive ventilation due to pulmonary infection accompanied by respiratory failure. After recovering, the patient was discharged in a clinically stable condition. One month later, the patient underwent another valve therapy in the contralateral left lower lobe without any complications. Ninety-five days after valve removal from the right lower lobe, the patient was admitted to hospital for hemoptysis. Computed tomography showed pulmonary infiltrates in the right lower lobe. Bronchoscopy with endoscopic instillation of fibrin and gauze tamponade in the right lower lobe was performed for management of hemoptysis and anticoagulant therapy was stopped. Furthermore, valves of the left lower lobe were removed to
Table 2. Changes of lung function parameters from baseline (prior to valve placement) to follow-up (immediately prior to valve removal) after a mean time of 590 days (range 93-2,177 days; $n=74$ )

\begin{tabular}{lccr}
\hline & $n$ & Mean \pm SD & $p$ value \\
\hline$\Delta$ VC, $\mathrm{L}$ & 74 & $-0.41 \pm 0.55$ & 1.000 \\
$\Delta \mathrm{VC}^{\circ} \%$ & 74 & $-10.83 \pm 16.06$ & 1.000 \\
$\Delta \mathrm{FEV}_{1}, \mathrm{~L}$ & 74 & $-0.10 \pm 0.13$ & 1.000 \\
$\Delta \mathrm{FEV}_{1}, \%$ & 74 & $-3.40 \pm 5.41$ & 1.000 \\
$\Delta \mathrm{RV}_{\mathrm{L}} \mathrm{L}$ & 73 & $0.50 \pm 1.11$ & $<0.001$ \\
$\Delta \mathrm{RV}, \%$ & 73 & $17.98 \pm 48.04$ & 0.001 \\
$\Delta \mathrm{TLC}, \mathrm{L}$ & 73 & $0.09 \pm 0.95$ & 0.199 \\
$\Delta \mathrm{TLC}, \%$ & 73 & $1.39 \pm 16.47$ & 0.237 \\
\hline
\end{tabular}

$\mathrm{VC}$, vital capacity; $\mathrm{FEV}_{1}$, forced expiratory volume in $1 \mathrm{~s} ; \mathrm{RV}$, residual volume; TLC, total lung capacity.

avoid any secretion retention that may trigger the pulmonary infection. Due to ongoing severe bleeding, the patient underwent thoracotomy for lobectomy of the right lower lobe. However, the patient developed respiratory failure and died 120 days after valve removal despite intensive care treatment.

\section{Changes of Lung Function prior to and following}

Valve Removal

Prior to valve placement, lung function tests of all patients showed a reduced mean $\mathrm{FEV}_{1}$ of $0.8 \pm 0.2 \mathrm{~L}(31 \pm 8 \%)$ and a severe hyperinflation with an increased mean residual volume of $5.3 \pm 1.3 \mathrm{~L}(247 \pm 54 \%)$. Patient demographics prior to endoscopic valve therapy are presented in Table 1.

In 75 out of the 76 patients, lung function test was performed immediately prior to valve removal, demonstrating a statistically significant deterioration of residual volume (L and \%) after a mean time of 590 days (range 932,177 days), which is most likely associated with COPD progression (Table 2). Bronchoscopic valve removal did not influence the lung function parameters significantly. Moreover, the rate of change/month of the various lung function parameters did not differ significantly prior to and following valve removal. Changes of lung function parameters are presented in Tables 3 and 4.

\section{Discussion}

Endoscopic valve therapy is currently the only reversible technique that reduces hyperinflation in patients with severe emphysema. It is postulated that these one- 
Table 4. Changes of lung function parameters before valve removal (rate of change/month) and after valve removal (rate of change/ month)

\begin{tabular}{lcccc}
\hline & $n$ & $\begin{array}{l}\text { Rate of change per } \\
\text { month before } \\
(\text { mean } \pm \text { SD) }\end{array}$ & $\begin{array}{l}\text { Rate of change per } \\
\text { month after } \\
(\text { mean } \pm \text { SD) }\end{array}$ & $p$ value \\
\hline VC, L & 59 & $-0.038 \pm 0.056$ & $-0.002 \pm 2.448$ & 0.545 \\
$\mathrm{VC}^{\circ} \%$ & 59 & $-1.048 \pm 1.659$ & $1.132 \pm 81.340$ & 0.581 \\
$\mathrm{FEV}_{1}, \mathrm{~L}$ & 59 & $-0.007 \pm 0.012$ & $0.123 \pm 0.621$ & 0.942 \\
$\mathrm{FEV}_{1,} \%$ & 59 & $-0.296 \pm 0.622$ & $3.867 \pm 24.728$ & 0.898 \\
$\mathrm{RV}_{\text {L }}$ & 59 & $0.037 \pm 0.067$ & $-0.280 \pm 3.720$ & 0.258 \\
$\mathrm{RV}, \%$ & 59 & $1.467 \pm 2.944$ & $-15.727 \pm 215.429$ & 0.271 \\
$\mathrm{TLC}, \mathrm{L}$ & 59 & $0.001 \pm 0.059$ & $-0.317 \pm 2.780$ & 0.192 \\
$\mathrm{TLC}, \%$ & 59 & $0.003 \pm 1.046$ & $-7.064 \pm 46.254$ & 0.123 \\
\hline
\end{tabular}

$\mathrm{VC}$, vital capacity; $\mathrm{FEV}_{1}$, forced expiratory volume in $1 \mathrm{~s} ; \mathrm{RV}$, residual volume; TLC, total lung capacity.

way valves may be removed in case of treatment failure or complications.

In RCTs related to valve therapy - BeLieVeR-HIFi, STELVIO, IMPACT, and TRANSFORM - permanent or temporary valve removal was described in 10\% (16/167) of the patients within the first 3 or 6 months following valve placement. The most common reasons for valve removal were pneumothorax $(7-12 \%)$, torsion of the left lower lobe bronchus after left upper lobe treatment (6\%), treatment failure $(2-6 \%)$, valve migration $(2-6 \%)$, or cough (4\%) [2-5]. In STELVIO, IMPACT, and TRANSFORM, the authors did not report any complications that were associated with valve removal within the first 6 months [3-5]. In the BeLieVeR-HIFi study, however, the authors described a difficult valve removal at 49 days due to development of cough after valve implantation in one patient (4\%). At the time of removal, the patient experienced a tension pneumothorax, progressed to respiratory failure, and died 17 days later [2]. So far, there are no comprehensive data about valve removal $>6$ months following valve implantation.

In this analysis, the most common indication for valve removal was treatment failure in contrast to findings in the RCTs, where the advent of pneumothorax was the most common reason for valve removal [7]. As pneumothorax as anticipated complication usually occurs within the first 3 days following implantation, it plays only a minor role in the time period $>180$ days since implantation. Furthermore, it must be kept in mind that in this analyzed patient cohort, also patients with significant interlobar collateral ventilation underwent valve therapy as the impact of collateral ventilation as predictor for successful valve therapy was not known until 2010. This could also have contributed to the fact that treatment failure was found to be the most common indication for valve removal in our patient cohort. It can be assumed that nowadays the rate of treatment failure resulting in valve removal is lower due to optimized patient selection.

Endoscopic findings after a mean time of 624 days since valve placement revealed clinical significant secretion and mucous plugging in $34 \%$ of the analyzed patients and there was a need for antibiotic therapy in 34\% after endoscopic procedure. The valve as a foreign body impairs the mucociliary clearance leading to retention of secretions in the area of the valves. The retained secretions can form bigger mucous films that may compromise the valve function and can stimulate colonization of bacteria. It is also already known that emphysema patients treated with valves show an increase in bacterial growth $>12$ months after valve placement [8]. However, the impact of mucous plugging on exacerbation rate has not been sufficiently studied. In the present study, pneumonia distal to the valves was the indication for valve removal in $9 \%$ of the analyzed patients. However, the overall incidence of post-obstructive pneumonia with the need of valve removal that occurred $>6$ months since implantation was only $1.6 \%(7 / 449)$ over a mean time of $\sim 21$ months. This finding was similar to those of the RCTs where rates of post-obstructive pneumonia of $1-4 \%$ in the earlier and shorter time period (within the first 3-6 months) were reported $[3,6,9]$.

Granulation tissue formation was found in $40 \%$ of the patients after a mean time of 624 days since valve placement. It is known that therapeutic interventions, where a foreign body is left in the airways, promote the formation of tissue granulation, e.g., airway stenting or tracheostomy $[10,11]$. Granulation tissue formation after airway stenting has already been thoroughly studied. Mechanical stress results from the forces exerted by the implanted devices as well as the stress from global lung motion and local contact pressure resulting in nonspecific inflammatory process and zones of superficial necrosis $[12,13]$. In addition, it seems that bacterial colonization is increased after valve placement and acts as a promoter for granulation tissue formation $[8,14]$. The valve-induced granulation tissue may lead to subsequent complications, e.g., mild hemoptysis or mucous plugging. Moreover, exophytic granulation tissue can impair valve function or may impede the valve removal in case 
it is required. In this analysis, the bronchoscopic valve removal was complicated in 4 patients (5\%) - in both cases, hyperplastic granulation tissue was observed. It has to be kept in mind though that valve-induced granulation tissue on a lobar, segmental, or subsegmental level may not always pose a problem but may also support lobar occlusion necessary for the desired lobar atelectasis. Therefore, no specific therapy is generally required if no problems occur. In case of hemoptysis or valve dysfunction, cryotherapy or mechanical debulking can be performed for the treatment of the granulation tissue formation.

Valve removal using flexible forceps was straightforward in the majority of our patients - only in 5\% of the patients, valve removal was technically complicated prolonging the intervention. In 3\% of the patients, a further bronchoscopy was required in order for all valves to be removed and in $5 \%$, one valve could not be removed. Bleeding occurred in $4 \%$ during endoscopic valve removal, but could be managed by instillation of topical vasoconstrictive agents or temporary gauze tamponade. As valve removal is commonly an elective intervention, we recommend stopping therapeutic anticoagulation or antiplatelet medication (except for low-dose acetylsalicylic acid) prior to the endoscopic valve removal. There was one fatal pneumonia accompanied by severe hemoptysis 120 days following valve removal in our patient cohort. However, the hemoptysis was unlikely associated with the endoscopic valve removal, as the endoscopic procedure ran without any complications. Also, the pneumonia is unlikely due to the valve removal given the long time period of 120 days between the bronchoscopy and the advent of pneumonia.

It must be noted that in our institution, all therapeutic procedures, e.g., valve implantation and valve removal, are routinely performed using rigid bronchoscopy under general anesthesia. Therefore, no statement can be made whether more complications may have occurred under flexible bronchoscopy alone under sedation and local anesthesia.

Following bronchoscopic valve removal, $8 \%$ of the patients complained about increased dyspnea, and after exclusion of differential diagnosis on the assumption of COPD exacerbation, steroid therapy was started. It is, however, uncertain if COPD exacerbation occurred due to the bronchoscopic procedure itself or due to the valve removal. It is known that bronchoscopies lead to a significant temporary decrease in $\mathrm{FEV}_{1}$ and forced vital capacity in healthy subjects as well as in patients with asthma, but there are only limited data about the exac- erbation rate following endoscopic procedures in COPD patients [15]. Hattotuwa and colleagues [16], who evaluated the safety of bronchoscopy in 57 patients with mild, moderate, or severe COPD, reported bronchospasm after bronchoscopy in $2 \%$ requiring 4 days of inpatient treatment. However, these data are very limited and do not provide a general statement on the incidence of exacerbation following bronchoscopic procedures in COPD patients. In the latest RCTs related to valve treatment, there was no statistical significant difference of the COPD exacerbation rate (with need of hospitalization) between the treatment group (9-20\%) and the control group (6-12\%); furthermore, the authors did not describe any COPD exacerbations following valve removal performed in 16 COPD patients [25]. In the present analysis, we also did not find a significant deterioration of lung function parameters following valve removal.

However, we recommend strict monitoring of the COPD patients after bronchoscopic valve removal as these patients have only a limited pulmonary reserve. In the present analysis, invasive ventilation was necessary in $3 \%$ and noninvasive ventilation in $7 \%$ of the patients due to respiratory failure.

Summarizing, endoscopic valve removal can be accompanied by increased dyspnea (8\%), bleeding (4\%), and respiratory failure (9\%), which may present remarkable complications in this patient cohort with limited pulmonary reserve. Therefore, one important question is if valve removal is really necessary in case of treatment failure without complications (e.g., pneumonia distal to the valves). Valves present foreign bodies that may irritate the bronchial mucosae, impair the mucociliary clearance, and may increase the bacterial colonization. However, so far it is not known if these local alterations have clinical relevance. Therefore, the benefits and risks of valve removal to the individual patient are weighed each uniquely, whereby the number of COPD exacerbations, amounts of sputum, or the occurrence of pneumonia should be taken into account.

In conclusion, the present report demonstrates that endoscopic valve removal $>6$ months after implantation is feasible and associated with an acceptable risk profile. Thus, valve treatment presents a reversible therapeutic method even after a long period of time. Close monitoring of these patients with limited pulmonary reserve is recommended, with particular attention to COPD exacerbations and respiratory failure. 


\section{Disclosure Statement}

D.G.: Lecture and travel fees from Pulmonx, Olympus, Uptake Medical, Chiesi, Boehringer Ingelheim, Novartis, Astra Zeneca, Munidpharma, Berlin Chemie, and Grifols. V.G.: No conflicts of interest. K.K.: No conflicts of interest. M.S.: Fees for lectures and advisory boards from the following companies: Olympus, Pul- monx, Astra Zeneca, Novartis, Teva, GSK, PneumRx, and Boston Scientific. R.E.: Lecture and travel fees from Olympus, Pulmonx, and Uptake Medical. F.J.F.H.: Fees for lectures and advisory boards from Astra, Allmirall, Berlin Chemie, Boehringer, Roche, GSK, Pulmonx, BTG, Olypmus, PneumRx, Boston Scientific, Medupdate, Grifols, CSL Behring, Omniamed, Lilly, Novartis, Teva, Uptake, and Vital Air. M.P.: No conflicts of interest.

\section{References}

1 Gompelmann D, Sarmand N, Herth FJ: Interventional pulmonology in chronic obstructive pulmonary disease. Curr Opin Pulm Med 2017;23:261-268

2 Davey C, Zoumut Z, Jordan S, McNulty WH, Carr DH, Hind MD, Hansell DM, Rubens MB, Banya W, Polkey MI, Shah PL, Hopkinson NS: Bronchoscopic lung volume reduction with endobronchial valves for patients with heterogeneous emphysema and intact interlobar fissures (the BeLieVeR-HIFi study): a randomised controlled trial. Lancet 2015;386:2066-2073.

3 Klooster $\mathrm{K}$, ten Hacken NH, Hartman JE, Kerstjens HA, van Rikxoort EM, Slebos DJ: Endobronchial valves for emphysema without interlobar collateral ventilation. N Engl J Med 2015;373:2325-2335.

4 Valipour A, Slebos DJ, Herth F, Darwiche K, Wagner M, Ficker JH, Petermann C, Hubner RH, Stanzel F, Eberhardt R; IMPACT Study Team: Endobronchial valve therapy in patients with homogeneous emphysema. Results from the IMPACT study. Am J Respir Crit Care Med 2016;194:1073-1082.

5 Kemp SV, Slebos DJ, Kirk A, Kornaszweska M, Carron K, Ek L, Broman G, Hillerdal G, Mal H, Pison C, Briault A, Downer N, Darwiche K, Rao J, Hübner RH, Ruwwe-Glosenkamp C, Trosini-Desert V, Eberhardt R, Herth FJ, Derom E, Malfait T, Shah PL, Garner JL, Ten Hacken NH, Fallouh H, Leroy S, Marquette CH; TRANSFORM Study Team: A Multicenter RCT of Zephyr ${ }^{\circledR}$ Endobronchial Valve Treatment in Heterogeneous Emphysema (TRANSFORM). Am J Respir Crit Care Med 2018 (Epub ahead of print).
6 Sciurba FC, Ernst A, Herth FJF, Strange C, Criner GJ, Marquette CH, Kovitz KL, Chiacchierini RP, Goldin J, McLennan G; VENT Study Research Group: A randomized study of endobronchial valves for advanced emphysema. N Engl J Med 2010;363:1233-1244.

7 Gompelmann D, Benjamin N, Kontogianni K, Herth F, Heussel CP, Hoffmann H, Eberhardt R: Clinical and radiological outcome following pneumothorax after endoscopic lung volume reduction with valves. Int J Chron Obstruct Pulmon Dis 2016;11:30933099.

8 Sarmand N, Gompelmann D, Kontogianni K, Polke M, Herth FHF, Eberhardt R: New bacterial growth in bronchial secretions after bronchoscopic valve implantation. ERS 2017;Abstract 813.

9 Herth FJ, Noppen M, Valipor A, Leroy S, Vergnon JM, Ficker JH, Egan JJ, Gasparini S, Agusti C, Holmes-Higgin D, Ernst A; International VENT Study Group: Efficacy predictors of lung volume reduction with Zephyr valves in a European cohort. Eur Respir J 2012;39:1334-1342.

10 Chung FT, Chen HC, Chou CL, Yu CT, Kuo $\mathrm{CH}$, Kuo HP, Lin SM: An outcome analysis of self-expandable metallic stents in central airway obstruction: a cohort study. J Cardiothorac Surg 2011;6:46.
11 Ledl C, Mertl-Roetzer M: Tracheal and tracheostomal hypergranulation and related stenosis in long-term cannulated patients: does the tracheostomy procedure make a difference? Ann Otol Rhinol Laryngol 2009;118: 876-800

12 McGrath DJ, Thiebes AL, Cornelissen CG O'Shea MB, O'Brien B, Jockenhoevel S, Bruzzi M, McHugh PE: An ovine in vivo framework for tracheobronchial stent analysis. Biomech Model Machenobiol 2017 (Epub ahead of print).

13 Grewe PH, Müller KM, Lindstaedt M, Germing A, Müller A, Mügge A, Deneke T: Reaction patterns of the tracheobronchial wall to implanted noncovered metal stents. Chest 2005; 128:986-990.

14 Nouraei SA, Petrou MA, Randhawa PS, Singh A, Howard DJ, Sandhu GS: Bacterial colonization of airway stents: a promoter of granulation tissue formation following laryngotracheal reconstruction. Arch Otolaryngol Head Neck Surg 2006;132:1086-1090.

15 Spanevello A, Migliori GB, Satta A, Sharara A, Ballardini L, Ind PW, Neri M: Bronchoalveolar lavage causes decrease in $\mathrm{PaO} 2$, increase in (A-a) gradient value and bronchoconstriction in asthmatics. Respir Med 1998;92:191-197.

16 Hattotuwa K, Gamble EA, O'Shaughnessy T, Jeffery PK, Barnes NC: Safety of bronchoscopy, biopsy, and BAL in research patients with COPD. Chest 2001;122:1909-1912. 